\title{
RBFOX1, encoding a splicing regulator, is a candidate gene for aggressive behavior
}

Noèlia Fernàndez-Castillo a , b , c , d , Gabriela Gan e , Marjolein M.J. van Donkelaar f , Mariliis Vaht g, Heike Weber h , i , Wolfgang Retz j, Andreas Meyer-Lindenberg e , Barbara Franke f, k, Jaanus Harro g, Andreas Reif h, Stephen V. Faraone l, m , Bru Cormand a , b , c , d

a Departament de Genètica, Microbiologia i Estadística, Facultat de Biologia, Universitat de Barcelona, Barcelona, Catalonia, Spain

b Centro de Investigación Biomédica en Red de Enfermedades Raras (CIBERER), Instituto de Salud Carlos III, Spain

c Institut de Biomedicina de la Universitat de Barcelona (IBUB), Barcelona, Catalonia, Spain

d Institut de Recerca Sant Joan de Déu (IR-SJD), Esplugues de Llobregat, Catalonia, Spain

e Department of Psychiatry and Psychotherapy, Central Institute of Mental Health, Medical Faculty

Mannheim/Heidelberg University, Mannheim, Germany

f Radboud university medical center, Donders Institute for Brain, Cognition and Behaviour, Department

of Human Genetics, Nijmegen, The Netherlands

g Division of Neuropsychopharmacology, Department of Psychology, University of Tartu, Tartu, Estonia

h Deptartment of Psychiatry, Psychosomatic Medicine and Psychotherapy, University Hospital Frankfurt -

Goethe University, Frankfurt am Main, Germany

i Department of Psychiatry, Psychosomatic Medicine and Psychotherapy, University Hospital of Würzburg,

Würzburg, Germany

j Department of Psychiatry and Psychotherapy, University Medical Center Mainz, Mainz, Germany

${ }_{k}$ Radboud university medical center, Donders Institute for Brain, Cognition and Behaviour, Department

of Psychiatry, Nijmegen, The Netherlands

I Departments of Psychiatry and of Neuroscience and Physiology, SUNY Upstate Medical University,

Syracuse, NY, USA

$\mathrm{m}$ K.G. Jebsen Centre for Research on Neuropsychiatric Disorders, University of Bergen, Bergen, Norway

\section{Abstract}

The RBFOX1 gene (or A2BP1) encodes a splicing factor important for neuronal development that has been related to autism spectrum disorder and other neurodevelopmental phenotypes. Evidence from complementary sources suggests that this gene contributes to aggressive behavior. Suggestive associations with RBFOX1 have been identified in genome-wide association studies (GWAS) of anger, conduct disorder, and aggressive behavior. Nominal association signals in RBFOX1 were also found in an epigenome-wide association study (EWAS) of aggressive behavior. Also, variants in this gene affect temporal lobe volume, a brain area that is altered in several aggression-related phenotypes. In animals, this gene has been shown to modulate aggressive behavior in Drosophila. RBFOX1 has also been associated with canine aggression and is upregulated in mice that show increased aggression after frustration of an expected reward. Associated common genetic variants as well as rare duplications and deletions affecting RBFOX1 have been identified in several psychiatric and neurodevelopmental disorders that are often 
comorbid with aggressive behaviors. In this paper, we comprehensively review the cumulative evidence linking RBFOX1 to aggression behavior and provide new results implicating RBFOX1 in this phenotype. Most of these studies (genetic and epigenetic analyses in humans, neuroimaging genetics, gene expression and animal models) are hypothesis-free, which strengthens the validity of the findings, although all the evidence is nominal and should therefore be taken with caution. Further studies are required to clarify in detail the role of this gene in this complex phenotype.

\section{Introduction}

Aggressive behavior and violence are major causes of mortality and morbidity in humans. These traits are observed in several psychiatric and neurodevelopmental disorders. Aggressive behavior is an evolutionary conserved trait of high importance for species survival. For this reason, it has been subject to selection throughout evolution and has a substantial genetic underpinning, while staying responsive to environmental cues. Accordingly, the heritability of aggressive behaviors has been estimated to be around 50\% (reviewed by Veroude et al. (2016)). Several genes and pathways contributing to aggression have been identified, such as those involved in the serotonergic and dopaminergic neurotransmission and in hormone regulation, although most of the genetic contribution to aggression is still unexplained (Fernàndez-Castillo and Cormand, 2016).

In a recent review on the genetics of human aggressive behavior, we searched for genes and pathways involved in this phenotype using data from genome-wide association studies (GWAS), which so far have not produced genome-wide significant genes/loci (Fernàndez-Castillo and Cormand, 2016). Among others, we highlighted the RBFOX1 gene (also known as A2BP1), which showed suggestive associations in three different GWAS (Anney et al., 2008; Mick et al., 2014; Sonuga-Barke et al., 2008). Interestingly, other complementary sources of evidence provide additional support for the contribution of this gene to the susceptibility to aggressive behavior and to several psychiatric disorders as well. RBFOX1 encodes the RNA Binding Protein, Fox-1 Homolog 1, also known as Ataxin-2-binding protein. It is expressed mainly in the nervous system, heart, and muscle (Jin et al., 2003; Underwood et al., 2005). The gene encodes a splicing factor that plays an important role in the regulation of the alternative splicing of large neuronal gene networks important for brain development (Bill et al., 2013; Conboy, 2017; Li et al., 2015). Cytoplasmic and nuclear $R B F O X 1$ isoforms seem to play different roles, with the first one 
contributing to mRNA stability and promoting translation and the second one acting as a splicing regulator (Hamada et al., 2016; Lee et al., 2016). The nuclear isoform is involved in neuron migration and synapse network formation during corticogenesis (Hamada et al., 2016) and is important for the control of neuronal excitation in the mammalian brain (Gehman et al., 2011). Alterations in the RBFOX1 gene have been associated with several neurodevelopmental pathologies, especially autism spectrum disorder (reviewed by Bill et al. (2013)).

Here, we review the cumulative evidence supporting a contribution of RBFOX1 to aggressive behaviors and to other psychiatric and neurodevelopmental disorders that often display aggressive behavior. We also present hitherto unpublished data derived from genetic association and neuroimaging genetics studies supporting our hypothesis.

\section{2. $R B F O X 1$ and aggressive behavior in humans}

\subsection{Association studies}

In a previous review of the genetic basis of aggressive behavior in humans (Fernàndez-Castillo and Cormand, 2016), RBFOX1 showed suggestive associations ( $p<5 \mathrm{e}-05$, Table 1) with aggressive traits or diagnostic categories in three GWAS (Anney et al., 2008; Merjonen et al., 2011; Sonuga-Barke et al., 2008). A common variant located within the first intron of the RBFOX1 gene, rs6500744, was identified as one of the top association signals in a GWAS assessing gene by environment interactions (GxE) (Sonuga-Barke et al., 2008). The $\mathrm{C}$ allele of this single nucleotide polymorphism (SNP) was associated with conduct disorder (CD) symptoms in interaction with mothers' warmth (Table 1 , Figure 1 ). Another SNP, also located in intron 1 of RBFOX1, rs8062784, was associated with anger in a GWAS assessing hostility in adolescents and adults (Merjonen et al., 2011 ), and two variants located in intron 3 of the gene, rs10153149 and rs12921846, were associated with CD in a sample of ADHD trios (Anney et al., 2008) (see Table 1 and Figure 1).

\begin{tabular}{|c|c|c|c|c|c|c|c|c|c|}
\hline SNP & Reference (GWAS) & Chr & bp (GRCh38) & Alleles $^{2}$ & $\mathrm{MAF}^{\mathrm{D}}$ & Phenotype associated & Sample & P-value & Risk allele \\
\hline rs6500744 & Sonuga-Barke et al., 2008 & 16 & 6063660 & $C>T$ & 0.46 & $\begin{array}{l}\text { Conduct disorder symptoms interacting } \\
\text { with mother's warmth }\end{array}$ & 938 trios & $3.65-05$ & $\mathrm{C}$ \\
\hline rs 809682 & Pappa et al., 2016 & 16 & 6346372 & $T>A$ & 0.26 & Children's aggressive behavior & 18,988 children & $2.62 \backslash-04$ & $T$ \\
\hline rs 12922093 & Pappa et al., 2016 & 16 & 6346947 & $\mathrm{~T}>\mathrm{C}$ & 0.26 & Children's aggressive behavior & 18,988 children & $3.21-04$ & $\mathbf{T}$ \\
\hline rs 12373031 & Pappa et al., 2016 & 16 & 6347436 & $\mathrm{~T}>\mathrm{C}$ & 0.14 & Children's aggressive behavior & 18,988 children & $4.93-04$ & $\mathbf{T}$ \\
\hline rs 10521042 & Pappa et al., 2016 & 16 & 6349836 & $C>T$ & 0.14 & Children's aggressive behavior & 18,988 children & $4.35-04$ & C \\
\hline rs10153149 & Anney et al., 2008 & 16 & 6875239 & $A>C$ & 0.16 & Conduct disorder & 938 trios & $3.64-05$ & A \\
\hline
\end{tabular}

According to the forward strand.

binimum allele frequency in the European population from 1000 Genomes (http:// wmw. internationalgenome.org/). 


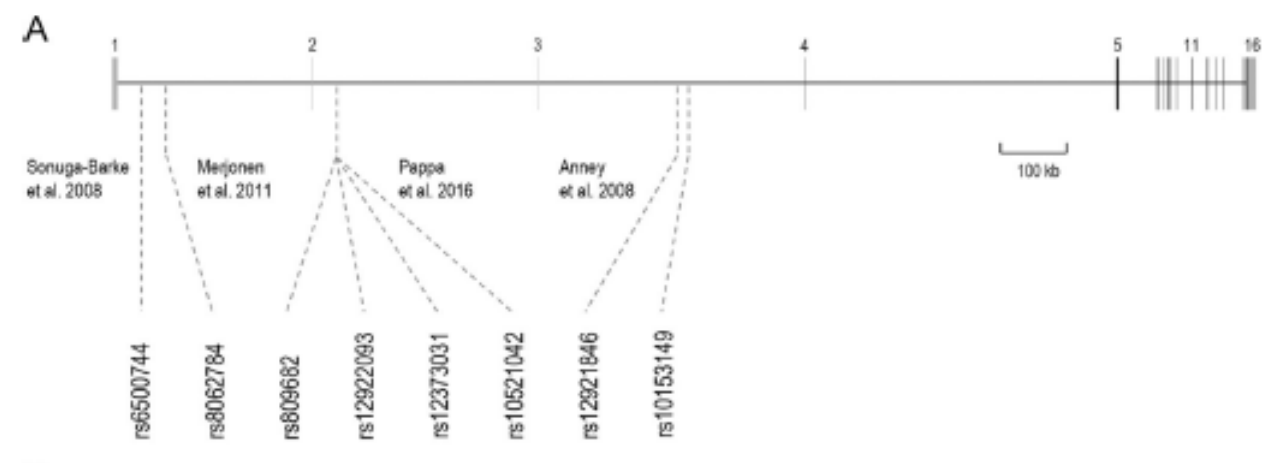

B

\begin{abstract}
Figure 1 (A) Diagram of the human RBFOX1 gene (NM_018723, GRCh38 Chr16: 6,019,131-7,713,338). Solid boxes indicate exons, with the coding regions in black and the non-coding ones in grey. Exon numbering is shown on top of the figure. Eight SNPs found nominally associated with aggressive phenotypes in several genome-wide association studies (GWAS) are shown below, with their locations indicated by discontinuous lines. (B) Linkage disequilibrium (LD) plot of the SNPs considering $r^{2}$, according to Haploview 4.2. Black boxes indicate complete LD and grey is for moderate LD.
\end{abstract}

A meta-analysis of nine population-based GWASs including around 19,000 children provided more evidence for the contribution of RBFOX1 to aggressive behavior (Pappa et al., 2016). Four SNPs in this gene (rs809682, rs12922093, rs12373031, and rs10521042, all located in intron 2) showed suggestive associations with children's aggressive behavior in a meta-analysis $(p<5 e$ -04, Table 1 and Figure 1, data kindly provided by the authors).

Overall, eight RBFOX1 variants from four GWASs showed a nominal association with aggression. The variants associated in each GWAS were not in linkage disequilibrium (LD) with those from the other studies. The LD between the four variants found associated in the meta-analysis (Pappa et al., 2016) was moderate to high. In an attempt to investigate the association of RBFOX1 with aggressive behavior further, we genotyped four SNPs (the most significant one from each GWAS) in a sample of German male prisoners, not included in any of the GWASs ( $n=188$, Supplementary material). A significant association was found for rs809682, when comparing aggressive prisoners to controls ( $p=0.03$, additive model) as well as aggressive prisoners to non-aggressive prisoners $(p=0.02)$, but not when comparing non-aggressive prisoners and controls $(p=0.76)$ (Supplementary Table 1). However, the direction of the effect was opposite as that of the original study, with the A allele linked to aggression (Supplementary Table 1 and Table 1). The same 
variant was also genotyped in a population-representative sample of 1176 individuals from the Estonian Children Personality Behaviour and Health Study, ECPBHS (Harro et al., 2001; Vaht et al., 2016) (see Supplementary material for details). Several traits related to aggressiveness were assessed in this population-based cohort, in particular those related to personality and anxiety. In the ECPBHS, five-factor personality data at young adulthood were available from the Estonian version of the NEO-PI-R questionnaire (Kallasmaa et al., 2000) and anxiety information from Spielberger's Trait Anxiety questionnaire (Spielberger, 1983). Aggressiveness is associated with certain facets in basic personality traits, in particular with low agreeableness and neuroticism (Caprara et al., 1996; Sharpe and Desai, 2001), and is also associated with anxiety (Clement and Chapouthier, 1998; Siddaway et al., 2017; Van Praag, 1998), higher negative emotionality (Caprara et al., 1996; Kodžopeljić et al., 2014; Tremblay and Ewart, 2005), and lower extraversion levels (Sharpe and Desai, 2001; Tremblay and Ewart, 2005). In the Estonian sample, rs809682 was nominally associated with extraversion $(p=0.024)$, the $\mathrm{T} / \mathrm{T}$ homozygotes showing the lowest levels of extraversion (Supplementary Table 2). We recently showed that sex can influence the contribution of genes to aggression (van Donkelaar et al., under review). We therefore also investigated genotype by sex interactions. RBFOX1 genotype and sex indeed had a significant interaction effect on agreeableness ( $p=6 \mathrm{e}-03$ ); male T/T homozygotes had the lowest scores of agreeableness. While NEO-PI neuroticism was not significantly associated with the genotype, data on Spielberger's Trait Anxiety showed a nominal association ( $p=0.043)$, with the T-allele carriers having higher levels of anxiety. Findings in the Estonian sample are in the direction expected for a gene associated with aggression, and suggest that higher expression of aggressive behavior in the T-allele carriers of the RBFOX1 rs809682 polymorphism may be related to basic personality traits and anxiety.

As indicated above, aggressive behavior is influenced by both genes and environment. For this reason, looking at epigenetic profiles linked to aggression also may provide insight into RBFOX1 's role. A recent epigenome-wide association study (EWAS) of aggressive behavior investigated DNA methylation levels associated with this phenotype in a sample of 2,029 individuals (van Dongen et al., 2015). This study did not produce any epigenome-wide significant findings, but two nominal associations between aggressive behavior and the methylation levels of sites located in RBFOX1 were identified at cg12310850 (GRCh37/hg19 position; chr16: 6,533,700, $p=8.7 \mathrm{e}-03$ ) and cg00499781 (chr16: 7,568,364, $p=0.040$ ) (data kindly provided by the authors). The authors 
also investigated the methylation levels of monozygotic twins highly discordant for aggression, identifying five nominal associations in sites located in RBFOX1 at cg03934713 (chr16: 6,069,198, $p=0.047)$, cg16396980 (chr16: 6,633,344, $p=0.041)$, cg06705265 (chr16: 6,696,222, $p=0.024)$, cg00514665 (chr16: 7,703,812, $p=0.049)$, and cg03986562 (chr16: 7,703,893, $p=0.037)$.

\subsection{Neuroimaging genetics studies and gene expression}

Human neuroimaging genetics studies suggest that the RBFOX1 gene contributes to brain function and structure. Thus, RBFOX1 has been shown to influence temporal lobe volume with genomewide significance in the Alzheimer's Disease Neuroimaging Initiative (ADNI) cohort including patients with Alzheimer's disease, patients with mild cognitive impairment, and cognitively healthy elderly controls (Kohannim et al., 2012b). In a related genome-wide study on the ADNI cohort, Kohannim et al. (2012a) observed that a variant in the RBFOX1 gene was highly predictive of temporal brain volume. The association between a specific variant in RBFOX1 and temporal lobe structure has been confirmed in voxel-wise whole-brain analyses in the ADNI cohort (Kohannim et al., 2012a, 2012b). In line with these findings, the RBFOX1 gene has been identified as specifically contributing to grey matter loss in the temporal lobe in patients with mild cognitive impairment, in a sample of Alzheimer's Disease (Vounou et al., 2012). While the aforementioned studies consistently show a link between $R B F O X 1$ and temporal lobe volume at genome-wide significance, caution in drawing conclusions for healthy younger adults is required as all findings are based on the ADNI cohort studying associations between temporal lobe volume in older adults with and without cognitive impairment and manifesting Alzheimer's disease. Thus, these associations between RBFOX1 and brain structure might be explained by the decline in temporal lobe volume observed in Alzheimer's disease and mild cognitive impairment (e.g., Vounou et al., 2012). Still, the link between RBFOX1 and temporal lobe volume is intriguing because Alzheimer's disease often presents with aggressive behavior (Zhao et al., 2016). Moreover, animal and human studies have underlined the role of the temporal lobe for aggression, especially with the amygdala and hippocampus being located in its medial part (Gregg and Siegel, 2001; Potegal, 2012; Siever, 2008). Abnormalities in temporal lobe function and structure have been observed in aggressive populations including individuals with conduct disorder (CD) (Cappadocia et al., 2009;

Kruesi et al., 2004), psychopathy (Raine et al., 2004), and aggressive schizophrenia (Hoptman et 
al., 2011; Soyka, 2011). Structural and functional changes in the temporal lobe in aggressive populations may be related to impaired emotion regulation (Bufkin, 2005) and/or to the lack of empathy in CD and antisocial behavior (Cappadocia et al., 2009). Still, although RBFOX1 seems to contribute to temporal lobe functioning, that does not directly support its contribution to aggressive behavior and further studies should investigate the effect of these variants.

In a recent study, we found the first evidence that the risk variant rs6500744 in the RBFOX1 gene, which had been associated with aggression in the GWAS of Sonuga-Barke et al. (2008), might be relevant to brain activity during neurocognitive processes such as inhibitory control and emotional reactivity (Gan et al., in preparation). In a sample of 331 healthy human participants, carriers of the risk allele $\mathrm{C}(\mathrm{C} / \mathrm{C}$ and $\mathrm{C} / \mathrm{T})$ showed an increased brain response in the dorsal anterior cingulate cortex (ACC) during emotion processing, and reduced brain responses in the left inferior/middle frontal gyrus during inhibitory control measured with a combined Flanker/Go-Nogo task. Moreover, we observed a sex by SNP interaction, in which female C/Ccarriers showed increased and male $\mathrm{C} / \mathrm{C}$-carriers showed decreased responding in the fusiform face area and the hypothalamus/ventral striatum compared to T-allele carriers during a Hariri emotional face recognition task (for fMRI tasks, compare (Meyer-Lindenberg et al., 2006)). Importantly, these findings converge with neuroimaging phenotypes including impaired brain functioning in prefrontallimbic networks during inhibitory control and emotional reactivity in carriers of the MAOA-L genotype, the most widely studied risk genotype for aggression (Alia-Klein et al., 2011; Buckholtz and Meyer-Lindenberg, 2008; Fan et al., 2003; Meyer-Lindenberg et al., 2006; Passamonti et al., 2006).

As expected, given its role in neurodevelopment, the expression of RBFOX1 in humans is mainly restricted to the brain, although it is also expressed in skeletal muscle and heart (Figure 2). Interestingly, the prefrontal cortex (PFC) including the anterior cingulate cortex (ACC) shows the highest RBFOX1 expression levels in humans (Figure 2). The PFC has been shown to play a role in impulsive aggression (Blair, 2016; Fan et al., 2003; Passamonti et al., 2006), most likely through its involvement in inhibitory control and behavioral self-regulation (Buckholtz and MeyerLindenberg, 2008; Davidson et al., 2000; Heatherton and Wagner, 2011). Also, ACC impaired functioning and structural abnormalities of this area has been repeatedly linked to a propensity for impulsive/reactive aggression (Buckholtz and Meyer-Lindenberg, 2008; Meyer-Lindenberg et al., 2006; Sterzer et al., 2005). Moreover, high expression levels of RBFOX1 are also found in the 
basal ganglia including the nucleus accumbens, putamen and caudate, brain areas previously linked to impulsive aggression across species (Buckholtz et al., 2010; Couppis and Kennedy, 2008; Ferrari et al., 2003; Gan et al., 2015; Krämer et al., 2007). A similar but less pronounced RBFOX1 expression level emerges for the amygdala, a crucial brain area for impulsive reactive aggression due to its involvement in emotional reactivity to threatening cues (Buckholtz et al., 2008; Coccaro et al., 2007; Meyer-Lindenberg et al., 2006). To conclude, although the observation of high RBFOX1 expression in brain areas relevant to aggression is interesting, this fact does not necessarily link this gene with aggression, as many other genes may show similar expression patterns and also many brain regions are involved in aggressive behavior. Future imaging genetic studies may shed light on the impact of RBFOX1 genotypes and pathways on brain function and structure within these areas.

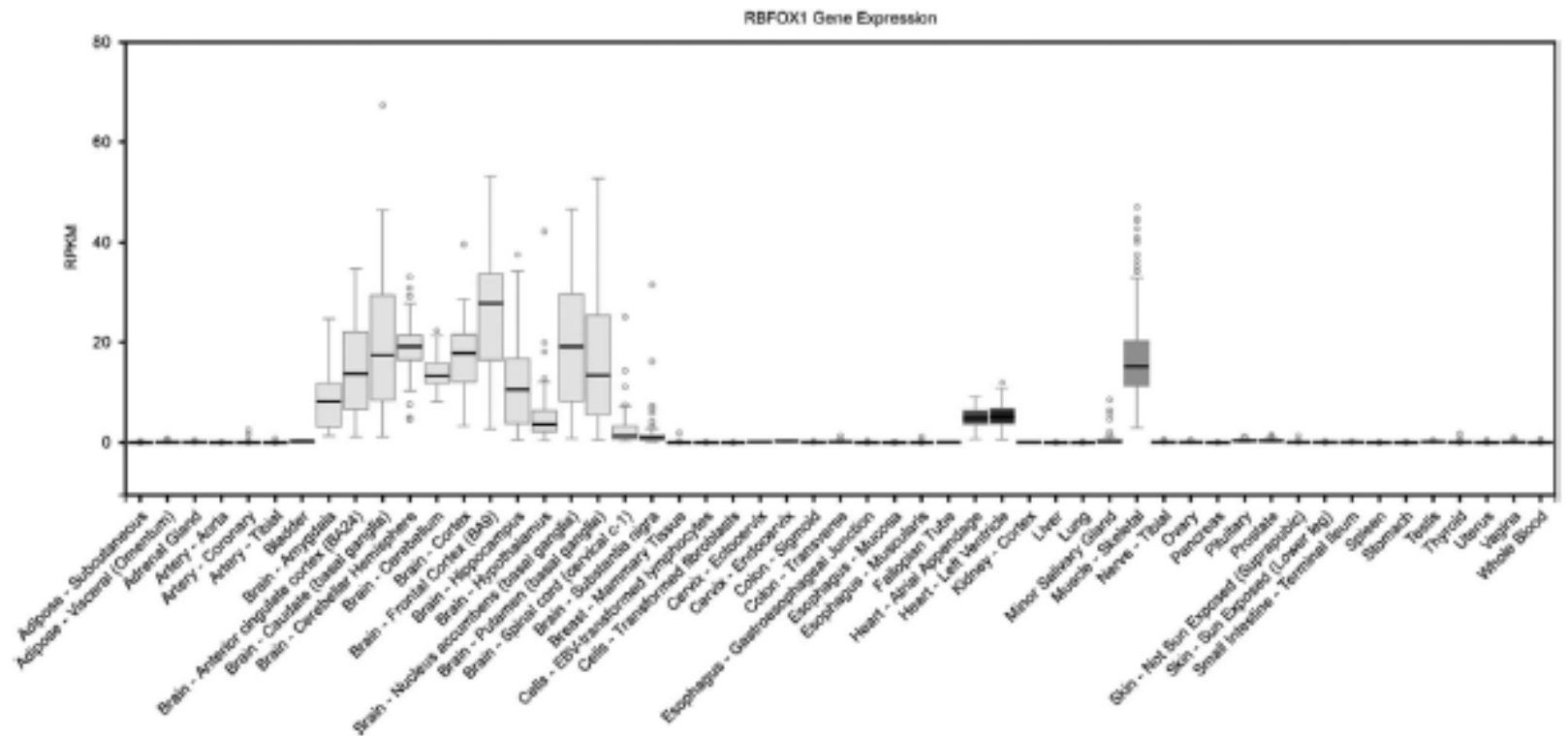

Figure 2 Expression of the RBFOX1 gene in different human tissues according to GTEx (wmw.gtexportal.org). RPKM: reads per kilobase per miltion mapped reads.

\section{3. $R B F O X 1$ and aggressive behavior in animals}

RBFOX1, also known as A2BP1, has been related to aggressive behavior in animal models of aggression. In Drosophila , A2bp1 was one of the genes identified through a genomewide analysis aimed at mapping loci involved in aggressive behavior (Shorter et al., 2015). The study used the sequenced inbred lines of the Drosophila melanogaster Genetic Reference Panel (DGRP) to 
investigate natural genetic variation related to aggression. Male-to-male aggression was quantified in 200 DGRP lines to identify the underlying genetic variation. Extreme quantitative trait locus (QTL) genome-wide association analysis was also performed in a population derived from DGRP lines with extremely high and extremely low aggression scores. From both analyses, the authors obtained a genetic interaction network with 741 genes, in which A2bp1 was present as an important node. The functional validation of the finding for the A2bp1 gene, using a mutant line with a $M i\{E T 1\}$ element insertional mutation, yielded significant evidence that homozygous mutant flies for this gene show decreased aggression $(p<0.001)$.

In a genome-wide mapping study of aggression in dogs, several nominal associations with A2bp1 were identified in two different cohorts (Zapata et al., 2016). Some of these signals in A2bp1 were associated with the four measures of aggression that were assessed: stranger-directed aggression (towards unfamiliar humans), dog-directed aggression (towards unfamiliar dogs), owner-directed aggression (towards familiar humans) and dog rivalry (towards familiar dogs). Four loci in A2bp1 were nominally associated with all four measures in one cohort (chr6: 35,449,934, chr6: 35,459,495, chr6: 35,557,330 and chr6: 35,557,812) and two in another cohort (chr6: 35,641,555 and chr6: 35,672,733).

Finally, in a murine model of frustration that showed increased aggressive behavior when the access to an expected reward was denied (Burokas et al., 2012), A2bp1 expression was upregulated (fold change $=1.32, p=1.29 \mathrm{e}-03$, FDR $<5 \%$ ) in ventral striatum of frustrated mice (MartínGarcía et al., 2015).

Mutant animal models of Rbfox 1 exist, but they have not been evaluated for aggressive behavior: a knockdown of rbfox1 in zebrafish was investigated for heart phenotypes and was shown to produce cardiac dysfunction and heart failure (Frese et al., 2015); knockout mice for Rbfox1 (-/-), central nervous system-specific, have been reported to present seizures and increased neuronal excitability (Gehman et al., 2011). Electrophysiological recordings of rat cortical neurons with increased expression of this gene also showed increased neuronal activity (Wen et al., 2015). A very recent study shows that RBFOX1 plays an important role in coordinating the synaptic downscaling of excitatory synapses (Rajman et al., 2017). Previous studies have reported that both excitatory and inhibitory neurotransmission are altered in aggression and that changes in neuronal excitation or inhibition modify aggressive behavior (Ende et al., 2015; Lin et al., 2011; Luque et 
al., 2009; Takahashi et al., 2015; Vekovischeva et al., 2004). Also, RBFOX1 is highly expressed in GABAergic neurons of the developing forebrain in mice (Hammock and Levitt, 2011). Thus, since changes in RBFOX1 seem to affect neuronal excitability, we could hypothesize that it may contribute to aggressive behavior by triggering alterations in inhibition/excitability balance, although no direct evidence of this has been observed so far. Further studies assessing aggressive behavior in knockout and knockin animals for $R b f o x 1$ are required to confirm this hypothesis and the role of this gene in this complex phenotype.

\section{RBFOX1 and psychiatric neurodevelopmental and neurodegenerative disorders}

Genetic variation in RBFOX1 - both common and rare - has been associated with anxiety disorder, substance use disorders, schizophrenia, bipolar disorder, attentiondeficit/hyperactivity disorder (ADHD), autism spectrum disorder (ASD) as well as Alzheimer disease. All these disorders present with aggressive behaviors (Brady et al., 1998; Bubier and Drabick, 2009; Fitzpatrick et al., 2016; Granic, 2014; Hoaken and Stewart, 2003; King and Waschbusch, 2010; Látalová, 2009; Volavka, 2013; Zhao et al., 2016).

Findings for associations with common variants in the gene originate mainly from GWAS. In anxiety disorder, a variant in intron 1 of the RBFOX1 gene (rs13334105) showed a genome-wide significant association with sensitivity to anxiety. Several other SNPs within the same intron also showed suggestive associations ( $p<1 \mathrm{e}-07$ ) (Davies et al., 2015). The authors also inspected this region in a GWAS metaanalysis of anxiety disorder and observed several nominal associations. RBFOX1 variants have been found associated with substance dependence and the ability to quit smoking in 13 different datasets (reviewed by Zhong et al. (2015)). Also, several genetic markers in a genomic region containing RBFOX1 displayed suggestive linkage to substance dependencerelated phenotypes (Zhong et al., 2015). For schizophrenia, suggestive associations were found with RBFOX1 in Ashkenazi Jews (Goes et al., 2015). Also, suggestive signals in this gene were found associated with both Schizophrenia and bipolar disorder (Wang et al., 2010). In Alzheimer disease, genome-wide significant signals have been identified in the gene (Herold et al., 201 ). Alzheimer Disease presents a high occurrence of aggression, estimated to occur in around $40 \%$ of individuals with this disorder (Zhao et al., 2016). 
Using the Ricopili web tool (https://data.broadinstitute. org/mpg/ricopili/) we identified additional common genetic variants in RBFOX1 that show suggestive association with several psychiatric phenotypes: bipolar disorder and schizophrenia (cross-disorder meta-analysis; rs12444931, $p=5 \mathrm{e}$ -06), schizophrenia (rs12447542, $p=1.1 \mathrm{e}-06$ ), smoking behavior (rs3112740, $p=6 \mathrm{e}-06$ ) and number of cigarettes per day (rs8055842, $p=3.4 \mathrm{e}-05$ ). Evidence for rare RBFOX1 variants being linked to brain disease come from several study designs. Copy number variants (CNVs) spanning the RBFOX1 gene have been reported in individuals with several psychiatric disorders. A partial duplication of RBFOX1 was associated with risk for schizophrenia, with an estimated eight-fold increased risk for males, but not for females (Melhem et al., 2011). Another partial duplication was identified in another patient with schizophrenia (Xu et al., 2008). A gain CNV spanning the first two exons of RBFOX1 and a loss in an intronic region have been reported for bipolar disorder (Noor et al., 2014). Also, hemizygous intronic RBFOX1 deletions and a duplication were identified in ADHD patients (Elia et al., 2010).

Another study identified CNVs in RBFOX1 in patients with neuropsychiatric and neurodevelopmental disorders such as ASD and global developmental delay, many of them presenting also with epilepsy (Zhao, 2013). Interestingly, in this study, one patient with intellectual disability, marked aggressive behavior, and epilepsy was found to bear a deletion in the RBFOX1 gene. Other studies identified deletions in RBFOX1 in autistic patients (Davis et al., 2012; Griswold et al., 2012; Martin et al., 2007; Sebat et al., 2007). One of these studies characterized a deletion in a proband with autism, global developmental delay, and epilepsy. The deletion was located at the boundary between the first exon and intron and reduced RBFOX1 mRNA expression in lymphocytes from the subject (Martin et al., 2007). More evidence connects RBFOX1 with ASD. A de novo truncating mutation in this gene and a duplication were identified in autistic patients (Griswold et al., 2015; Kanduri et al., 2016). A transcriptomic analysis of post-mortem autistic brains identified a module of co-expressed genes in which RBFOX1 was an important node (Voineagu et al., 2011). This gene module was enriched for associated genetic variants in an autism GWAS dataset. Furthermore, the authors performed RNAseq to compare brain samples of autistic patients with decreased expression of RBFOX1 (FC $=-5.9)$ and controls with average expression of this gene, and observed a broad dysregulation of alternative splicing in the brain of autistic patients that is dependent on RBFOX1 . 
Several genetic alterations in RBFOX1 have been identified in individuals with epilepsy, a neurological disorder that has also been related to aggressive behavior (Brodie et al., 2016). In line with this, as mentioned above, the knockout mice for Rbfox1 show susceptibility to seizures and increased neuronal excitability (Gehman et al., 2011). Another study observed upregulation of RBFOX1 in patients with malformed cortex and epilepsy, and showed that this upregulation produces an increase in the neuronal activity of rat cortical neurons (Wen et al., 2015).

The fact that RBFOX1 has been related to many psychiatric disorders make it an appealing candidate gene for aggression, although the increased incidence of aggression in many of these disorders does not connect RBFOX1 with aggressive behavior. In this regard, exploration of large cohorts of aggression is needed to investigate the effect of genetic variants in RBFOX1 that have been reported as risk factors for other psychiatric disorders. Also, we need to get more insight into the contribution to aggression of CNVs spanning RBFOX1 .

\section{Discussion and future perspectives}

In this review, we bring together different lines of evidence that implicate RBFOX1 in the etiology of aggressive behavior, including genetic association and mutation studies, neuroimaging genetics data, transcriptomic analyses, and animal models. Although the convergence of evidence is impressive, most of this supportive data is of nominal significance in the individual studies and should therefore be interpreted with caution.

Four independent GWASs (one of them including nine datasets) associated RBFOX1 with aggression. However, it should be noted that this gene spans a wide region in the genome (1.7 Mbp, more than 30 times the average length of a human gene) and carries many common variants, increasing the probability for identifying spurious associations. Speaking against such false positive effects, according to the GWAS catalog ( https://www.ebi.ac.uk/gwas/ ), so far only very few disease or trait associations have been identified for RBFOX1 with $p$-values $<1 \mathrm{e}-05$, (including obesity and body mass index, heart rate, periodontitis, and eye related diseases). In any case, we cannot discard that gene length may influence the appearance of false positive associations. Finally, given the high degree of phenotypic heterogeneity of aggressive behaviors, association studies in larger and more homogeneous samples are required to confirm the involvement of RBFOX1 . 
All the RBFOX1 variants identified by the different GWASs of aggression lie in the first three introns of the gene. This localization also applies to the SNPs and CNVs associated with other psychiatric disorders. This clustering of risk variants may be due to the presence of regulatory elements of RBFOX1 in this region, as suggested by others ( Martin et al., 2007 ). To our knowledge, CNVs in RBFOX1 have not been investigated in relation to aggressive behavior directly. Such studies may be informative as they have been for schizophrenia, bipolar disorder, ADHD or autism.

The neuroimaging genetics studies reported here highlight structural and functional brain alterations correlating with RBFOX1 variation, both in population-based cohorts and in clinical samples. These results point to the temporal lobe and to alterations in neurocognitive performance. However, to our knowledge, no investigations have been performed in clinical samples with pathological levels of aggression (e.g., conduct disorder, antisocial personality disorder, intermittent explosive disorder). Such studies may shed light on the functional significance of RBFOX1 with regard to brain regions previously linked to aggressive behavior, such as the temporal and frontal lobes, the basal ganglia and the amygdala, where the gene is highly expressed. Animal models can provide more insights into the role of this gene in aggression. The data from Drosophila reviewed above are convincing. In this regard (and given the Drosophila phenotype as well as the findings of duplications in the gene in human brain disorders), it might be interesting to assess aggressive behavior not only in knockout animals for RBFOX1, but also in knockin animals, where the gene is upregulated.

Taken together, evidence from complementary study designs point to RBFOX1 as a strong candidate for susceptibility to aggressive behavior and to several psychiatric disorders. Still, further association and neuroimaging genetics studies in larger samples, as well as studies in transgenic animals for $R B F O X 1$, are needed to confirm the contribution of this gene to aggression. If confirmation is obtained, RBFOX1 could be a promising pharmacological target for the treatment of aggression, given its broad role in the development and functioning of brain processes. 


\section{Role of the funding source}

The research leading to these results has received funding from the European Union Seventh Framework Programme [FP7/2007-2013] under grant agreements n ${ }^{\circ}$ 602805 , 602450 and 278948 and from the European Union H2020 Programme [H2020/2014-2020] under grant agreements n ${ }^{\circ}$ 643051 and 667302. Additionally, N. Fernàndez-Castillo is supported by a contract of the 'Centro de Investigación Biomédica en Red de Enfermedades Raras' (CIBERER) and B. Cormand by the Spanish 'Ministerio de Economía y Competitividad' (SAF2015-68341-R) and AGAUR, ‘ Generalitat de Catalunya ' ( 2014SGR932 ). Further funding was received from the European College of Neuropsychopharmacology (ECNP) by a grant for the ECNP Network 'ADHD across the lifespan'. G. Gan was supported by the German academic exchange service (DAAD), and the Olympia-Morata Program of the University of Heidelberg, Germany. J. Harro received funding from EMES Grant IUT-20-40. Prof. Faraone is supported by the K.G. Jebsen Centre for Research on Neuropsychiatric Disorders, University of Bergen, Norway, and NIMH grants 5R01MH101519 and U01 MH109536-01. Prof. B. Franke and M. van Donkelaar are supported by funding from a personal Vici grant of the Netherlands Organisation for Scientific Research (NWO; grant 016-130669 , to BF). None of the funding institutions had any role in study design; in the collection, analysis and interpretation of data; in the writing of the report; and in the decision to submit the paper for publication.

\section{Contributors}

N. Fernàndez-Castillo and B. Cormand identified the gene as a possible candidate and led the work and together with S.V. Faraone coordinated the study. N. Fernàndez-Castillo performed the literature review and wrote the first draft of the manuscript. B. Cormand and S.V. Faraone gathered new data. G. Gan, M.J. van Donkelaar, B. Franke and A. Meyer-Lindenberg performed neuroimaging genetic analyses. G. Gan contributed to the writing of the neuroimaging section. $\mathrm{H}$. Weber, A. Reif and W. Retz performed the association study in the German sample of prisoners, and M. Vaht and J. Harro in the Estonian sample. All authors contributed to the final version of the manuscript. 


\section{Conflict of interest}

None of the authors declare any conflict of interest.

\section{Acknowledgement}

We would like to thank the EAGLE consortium, Dorret Boomsma and Jenny van Dongen for kindly providing us with the results from their human GWAS and EWAS studies, and to Carlos Álvarez and Isain Zapata for the results of their study on canine aggression. We would like to thank Jeffrey Glennon, Heike Tost and Anais Harneit for providing useful comments and literature.

\section{Appendix A. Supporting information}

Supplementary data associated with this article can be found in the online version at https://doi.org/10.1016/j.euroneuro.2017.11.012 .

\section{References}

Alia-Klein, N. , Parvaz, M.A. , Woicik, P.A. , Konova, A.B. , Maloney, T. , Shumay, E. , Wang, R. , Telang, F. , Biegon, A. , Wang, G.-J. , Fowler, J.S. , Tomasi, D. , Volkow, N.D. , Goldstein, R.Z. , 2011. Gene x disease interaction on orbitofrontal gray matter in cocaine addiction. Arch. Gen. Psychiatry 68, 283-294 .

Anney, R.J.L. , Lasky-Su, J. , Ó’Dúshláine, C. , Kenny, E. , Neale, B.M. , Mulligan, A. , Franke, B. , Zhou, K. , Chen, W. , Christiansen, H. , Arias-Vásquez, A. , Banaschewski, T. , Buitelaar, J. , Ebstein, R. , Miranda, A. , Mulas, F. , Oades, R.D. , Roeyers, H. , Rothenberger, A. , Sergeant, J. , Sonuga-Barke, E. , Steinhausen, H. , Asherson, P. , Faraone, S.V. , Gil, M. , 2008. Conduct disorder and ADHD: evaluation of conduct problems as a categorical and quantitative trait in the international multicentre ADHD genetics study. Am. J. Med. Genet. Part B Neuropsychiatr. Genet. 147, 1369-1378 .

Bill, B.R. , Lowe, J.K. , DyBuncio, C.T. , Fogel, B.L. , 2013. Orchestration of neurodevelopmental programs by RBFOX1: implications for autism spectrum disorder. Int. Rev. Neurobiol. 113, 251267 .

Blair, R.J.R. , 2016. The neurobiology of impulsive aggression. J. Child Adolesc. Psychopharmacol. 26, 4-9 .

Brady, K.T. , Myrick, H. , McElroy, S.L. , 1998. The relationship between substance use disorders, impulse control disorders, and pathological aggression. Am. J. Addict. 7, 221-230 . 
Brodie, M.J. , Besag, F. , Ettinger, A.B. , Mula, M. , Gobbi, G. , Comai, S. , Aldenkamp, A.P. , Steinhoff, B.J. , 2016. Epilepsy, antiepileptic drugs, and aggression: an evidence-based review. Pharmacol. Rev. 68, 563-602 .

Bubier, J.L. , Drabick, D.A.G. , 2009. Co-occurring anxiety and disruptive behavior disorders: the roles of anxious symptoms, reactive aggression, and shared risk processes. Clin. Psychol. Rev. 29, 658-669 .

Buckholtz, J.W. , Callicott, J.H. , Kolachana, B. , Hariri, A.R. , Goldberg, T.E. , Genderson, M. , Egan, M.F. , Mattay, V.S. , Weinberger, D.R. , Meyer-Lindenberg, A. , 2008. Genetic variation in MAOA modulates ventromedial prefrontal circuitry mediating individual differences in human personality. Mol. Psychiatry 13, 313-324 .

Buckholtz, J.W. , Meyer-Lindenberg, A. , 2008. MAOA and the neurogenetic architecture of human aggression. Trends Neurosci. 31, 120-129 .

Buckholtz, J.W. , Treadway, M.T. , Cowan, R.L. , Woodward, N.D. , Benning, S.D. , Li, R. , Ansari, M.S. , Baldwin, R.M. , Schwartzman, A.N. , Shelby, E.S. , Smith, C.E. , Cole, D. , Kessler, R.M. , Zald, D.H. , 2010. Mesolimbic dopamine reward system hypersensitivity in individuals with psychopathic traits. Nat. Neurosci. 13, 419-421 .

Bufkin, J.L. , 2005. Neuroimaging studies of aggressive and violent behavior: current findings and implications for criminology and criminal justice. Trauma Violence Abus. 6, 176-191 .

Burokas, A. , Gutiérrez-Cuesta, J. , Martín-García, E. , Maldonado, R. , 2012. Operant model of frustrated expected reward in mice. Addict. Biol. 17, 770-782 .

Cappadocia, M.C. , Desrocher, M. , Pepler, D. , Schroeder, J.H. , 2009. Contextualizing the neurobiology of conduct disorder in an emotion dysregulation framework. Clin. Psychol. Rev. 29, 506-518 .

Caprara, G.V. , Barbaranelli, C. , Zimbardo, P.G. , 1996. Understanding the complexity of human aggression: affective, cognitive, and social dimensions of individual differences in propensity toward aggression. Eur. J. Pers. 10, 133-155 .

Clement, Y. , Chapouthier, G. , 1998. Biological bases of anxiety. Neurosci. Biobehav. Rev. 22, 623-633 .

Coccaro, E.F. , McCloskey, M.S. , Fitzgerald, D.A., Phan, K.L. , 2007. Amygdala and orbitofrontal reactivity to social threat in individuals with impulsive aggression. Biol. Psychiatry 62, 168-178.

Conboy, J.G. , 2017. Developmental regulation of RNA processing by Rbfox proteins. Wiley Interdiscip. Rev. RNA 8, e1398 . 
Couppis, M.H. , Kennedy, C.H. , 2008. The rewarding effect of aggression is reduced by nucleus accumbens dopamine receptor antagonism in mice. Psychopharmacology 197, 449-456 .

Davidson, R.J. , Putnam, K.M. , Larson, C.L. , 2000. Dysfunction in the neural circuitry of emotion regulation-a possible prelude to violence. Science 289, 591-594 (80-. ) .

Davies, M.N. , Verdi, S. , Burri, A. , Trzaskowski, M. , Lee, M. , Hettema, J.M. , Jansen, R. , Boomsma, D.I. , Spector, T.D. , 2015.

Generalised Anxiety Disorder - a twin study of genetic architecture, genome-wide association and differential gene expression. PLoS One 10, e0134865 .

Davis, L.K. , Maltman, N. , Mosconi, M.W. , Macmillan, C. , Schmitt, L. , Moore, K. , Francis, S.M. , Jacob, S., Sweeney, J.A. , Cook, E.H. , 2012. Rare inherited A2BP1 deletion in a proband with autism and developmental hemiparesis. Am. J. Med. Genet. Part A 158 A, 1654-1661 .

Elia, J. , Gai, X. , Xie, H.M. , Perin, J.C. , Geiger, E. , Glessner, J.T. , D’arcy, M. , DeBerardinis, R. , Frackelton, E. , Kim, C. , Lantieri, F. , Muganga, B.M. , Wang, L. , Takeda, T. , Rappaport, E.F. , Grant, S.F.A. , Berrettini, W. , Devoto, M. , Shaikh, T.H. , Hakonarson, H. , White, P.S. , 2010. Rare structural variants found in attention-deficit hyperactivity disorder are preferentially associated with neurodevelopmental genes. Mol. Psychiatry 15, 637-646 .

Ende, G. , Cackowski, S. , VanEijk, J. , Sack, M. , Demirakca, T. , Kleindienst, N. , Bohus, M. , Sobanski, E. , Krause-Utz, A. , Schmahl, C. , 2015. Impulsivity and aggression in female BPD and ADHD patients: association with ACC Glutamate and GABA aoncentrations. Neuropsychopharmacology 41, 410-418 .

Fan, J. , Fossella, J. , Sommer, T. , Wu, Y. , Posner, M.I. , 2003. Mapping the genetic variation of executive attention onto brain activity. Proc. Natl. Acad. Sci. USA 100, 7406-7411 .

Fernàndez-Castillo, N. , Cormand, B. , 2016. Aggressive behavior in humans: genes and pathways identified through association studies. Am. J. Med. Genet. Part B Neuropsychiatr. Genet. 171, 676-696.

Ferrari, P.F. , Van Erp, A.M.M. , Tornatzky, W. , Miczek, K.A. , 2003. Accumbal dopamine and serotonin in anticipation of the next aggressive episode in rats. Eur. J. Neurosci. 17, 371-378 .

Fitzpatrick, S.E. , Srivorakiat, L. , Wink, L.K. , Pedapati, E.V., Erickson, C.A. , 2016. Aggression in autism spectrum disorder: presentation and treatment options. Neuropsychiatr. Dis. Treat. 12, 1525-1538 .

Frese, K.S. , Meder, B. , Keller, A. , Just, S. , Haas, J. , Vogel, B. , Fischer, S. , Backes, C. , Matzas, M. , Köhler, D. , Benes, V. , Katus, H.A. , Rottbauer, W. , 2015. RNA splicing regulated by RBFOX1 is essential for cardiac function in zebrafish. J. Cell Sci. 128, 3030-3040 . 
Gan, G. , Sterzer, P. , Marxen, M. , Zimmermann, U.S. , Smolka, M.N. , 2015. Neural and behavioral correlates of alcohol-induced aggression under provocation. Neuropsychopharmacology 40, 2886-2896 .

Gehman, L.T. , Stoilov, P. , Maguire, J., Damianov, A. , Lin, C.-H. , Shiue, L. , Ares, M. , Mody, I. , Black, D.L. , 2011. The splicing regulator Rbfox1 (A2BP1) controls neuronal excitation in the mammalian brain. Nat. Genet. 43, 706-711 .

Goes, F.S. , Mcgrath, J. , Avramopoulos, D. , Wolyniec, P. , Pirooznia, M. , Ruczinski, I. , Nestadt, G. , Kenny, E.E. , Vacic, V. , Peters, I. , Lencz, T. , Darvasi, A. , Mulle, J.G. , Warren, S.T. , Pulver, A.E. , 2015. Genome-wide association study of schizophrenia in Ashkenazi Jews. Am. J. Med. Genet. Part B Neuropsychiatr. Genet 168, 649-659 .

Granic, I. , 2014. The role of anxiety in the development, maintenance, and treatment of childhood aggression. Dev. Psychopathol. 26, 1515-1530 .

Gregg, T.R. , Siegel, A. , 2001. Brain structures and neurotransmitters regulating aggression in cats: implications for human aggression. Prog. Neuro-Psychopharmacol. Biol. Psychiatry 25, 91140 .

Griswold, A.J. , Dueker, N.D. , Van Booven, D. , Rantus, J.A. , Jaworski, J.M. , Slifer, S.H. , Schmidt, M.A. , Hulme, W. , Konidari, I. , Whitehead, P.L. , Cuccaro, M.L. , Martin, E.R. , Haines, J.L. , Gilbert, J.R. , Hussman, J.P. , Pericak-Vance, M.A. , 2015. Targeted massively parallel sequencing of autism spectrum disorder-associated genes in a case control cohort reveals rare lossof-function risk variants. Mol. Autism 6, 43 .

Griswold, A.J. , Ma, D. , Cukier, H.N. , Nations, L.D. , Schmidt, M.A. , Chung, R.H. , Jaworski, J.M. , Salyakina, D. , Konidari, I. , Whitehead, P.L. , Wright, H.H. , Abramson, R.K. , Williams, S.M. , Menon, R. , Martin, E.R. , Haines, J.L. , Gilbert, J.R. , Cuccaro, M.L. , Pericak-Vance, M.A. , 2012. Evaluation of copy number variations reveals novel candidate genes in autism spectrum disorder-associated pathways. Hum. Mol. Genet. 21, 3513-3523 .

Hamada, N. , Ito, H. , Nishijo, T. , Iwamoto, I. , Morishita, R. , Tabata, H. , Momiyama, T. , Nagata, K.-I. , Shibata, H. , Huynh, D.P. , Pulst, S.M. , Jin, Y. , Underwood, J.G. , Boutz, P.L. , Dougherty, J.D. , Stoilov, P. , Black, D.L. , Zhou, H.L. , Baraniak, A.P. , Lou, H. , Lee, J.A. , Tang, Z.Z. , Black, D.L. , Gehman, L.T. , Zhang, C. , Philippe, A. , Bucan, M. , Abrahams, B.S. , Wang, K. , Glessner, J.T. , Gai, X. , Pinto, D. , Sanders, S.J. , Buxbaum, J.D. , Lucarelli, P. , Voineagu, I. , Weyn-Vanhentenryck, S.M. , Bhalla, K. , Elia, J. , Hamshere, M.L. , Xu, B. , Hamada, N. , Nakahata, S. , Kawamoto, S. , Kim, K.K. , Kim, Y.C. , Adelstein, R.S. , Kawamoto, S. , Konno, D. , Koresawa, Y. , Kawabata, I. , Umeda, T. , Yamamoto, K. , Okabe, S. , Hamada, N. , Hanai, N. , Nagata, K.-I. , Ito, H. , Iwamoto, I. , Morishita, R. , Asano, T. , Shinoda, T. , Ito, H. , Tabata, H. , Nakajima, K. , Uchino, S. , Nishimura, Y.V. , Shinoda, T. , Inaguma, Y. , Ito, H. , Nagata, K.I. , Gehman, L.T. , Lal, D. , Friocourt, G. , Tabata, H. , Nakajima, K. , Noctor, S.C. , MartínezCerdeño, V. , Ivic, L. , Kriegstein, A.R. , Solecki, D.J. , Model, L. , Gaetz, J. , Kapoor, T.M. , Hatten, M.E. , Tanaka, T. , Nadarajah, B. , Brunstrom, J.E. , Grutzendler, J. , Wong, R.O. , Pearlman, A.L. , Craig, A.M. , Banker, G. , Tepper, J.M. , Sharpe, N.A. , Koós, T.Z. , Trent, F. , 
Yoshikawa, G. , Sasaki, J. , Raj, B. , Blencowe, B.J. , Carninci, P. , Ihara, M. , Zhao, L. , LongoGuess, C. , Harris, B.S. , Lee, J.-W. , Ackerman, S.L. , Inaguma, Y. , Lee, J.-A. , Reiner, O. , Sapir, T. , Tsai, L.-H. , Gleeson, J.G. , Fogel, B.L. , Zhang, J. , O’Brien, J.E. , 2016. Essential role of the nuclear isoform of RBFOX1, a candidate gene for autism spectrum disorders, in the brain development. Sci. Rep. 6, 30805 .

Hammock, E.A.D. , Levitt, P. , 2011. Developmental expression mapping of a gene implicated in multiple neurodevelopmental disorders, A2bp1 (Fox1). Dev. Neurosci. 33, 64-74 .

Harro, M. , Eensoo, D. , Kiive, E. , Merenäkk, L. , Alep, J. , Oreland, L. , Harro, J. , 2001. Platelet monoamine oxidase in healthy 9- and 15-years old children: the effect of gender, smoking and puberty. Prog. Neuro-Psychopharmacol. Biol. Psychiatry 25, 1497-1511 .

Heatherton, T.F. , Wagner, D.D. , 2011. Cognitive neuroscience of self-regulation failure. Trends Cogn. Sci. 15, 132-139 .

Herold, C. , Hooli, B.V. , Mullin, K. , Liu, T. , Roehr, J.T. , Mattheisen, M. , Parrado, A.R. , Bertram, L. , Lange, C. , Tanzi, R.E. , 2016. Family-based association analyses of imputed genotypes reveal genome-wide significant association of Alzheimer's disease with OSBPL6, PTPRG, and PDCL3. Mol. Psychiatry 21, 1608-1612 .

Hoaken, P.N.S. , Stewart, S.H. , 2003. Drugs of abuse and the elicitation of human aggressive behavior. Addict. Behav. 28, 1533-1554 .

Hoptman, M.J. , Antonius, D. , Kline, N. , 2011. Neuroimaging correlates of aggression in schizophrenia: an update. Curr. Opin. Psychiatry 24, 100-106 .

Jin, Y. , Suzuki, H. , Maegawa, S. , Endo, H. , Sugano, S. , Hashimoto, K. , Yasuda, K. , Inoue, K. , 2003. A vertebrate RNA-binding protein Fox-1 regulates tissue-specific splicing via the pentanucleotide GCAUG. EMBO J 22, 905-912 .

Kallasmaa, T. , Allik, J. , Realo, A. , McCrae, R.R. , 2000. The Estonian version of the NEO-PI$\mathrm{R}$ : an examination of universal and culture-specific aspects of the five-factor model. Eur. J. Pers. 14, 265-278 .

Kanduri, C. , Kantojärvi, K. , Salo, P.M. , Vanhala, R. , Buck, G. , Blancher, C. , Lähdesmäki, H. , Järvelä, I. , 2016. The landscape of copy number variations in Finnish families with autism spectrum disorders. Autism Res. 9, 9-16.

King, S. , Waschbusch, D.A. , 2010. Aggression in children with attention-deficit/hyperactivity disorder. Expert Rev. Neurother. 10, 1581-1594 .

Kodžopelji 'c, J., Smederevac, S., Mitrovi 'c, D. , Dini 'c, B. , Colovi 'c, P. , 2014. School bullying in adolescence and personality traits: a person-centered approach. J. Interpers. Violence 29, 736-757 . 
Kohannim, O., Hibar, D.P., Jahanshad, N., Stein, J.L., Hu, X., Toga, A.W., Jack, C.R., Weiner, M.W., Thompson, P.M., the Alzheimer's Disease Neuroimaging Initiative, P.M., Initiative, T.D.N., 2012a. Predicting temporal lobe volume on MRI from genotypes using L(1)-L(2) regularized regression. In: Proceedings. IEEE International Symp. Biomed. Imaging 1160-1163.

Kohannim, O. , Hibar, D.P. , Stein, J.L. , Jahansha, N. , Hua, X. , Rajagopalan, P. , Toga, A.W. , Jack, C.R. , Weiner, M.W. , de Zubicaray, G.I. , McMahon, K.L. , Hansell, N.K. , Martin, N.G. , Wright, M.J. , Thompson, P.M. , 2012b. Discovery and replication of gene influences on brain structure using LASSO regression. Front. Neurosci. 6, 115 .

Krämer, U.M. , Jansma, H. , Tempelmann, C. , Münte, T.F. , 2007. Tit-for-tat: the neural basis of reactive aggression. Neuroimage 38, 203-211 .

Kruesi, M.J.P. , Casanova, M.F. , Mannheim, G. , Johnson-Bilder, A. , 2004. Reduced temporal lobe volume in early onset conduct disorder. Psychiatry Res. 132, 1-11.

Látalová, K. , 2009. Bipolar disorder and aggression. Int. J. Clin. Pract. 63, 889-899 .

Lee, J.A. , Damianov, A. , Lin, C.H. , Fontes, M. , Parikshak, N.N. , Anderson, E.S. , Geschwind, D.H. , Black, D.L. , Martin, K.C. , 2016. Cytoplasmic Rbfox1 regulates the expression of synaptic and autism-related genes. Neuron 89, 113-128 .

Li, Y.I, Sanchez-Pulido, L., Haerty, W., Ponting, C.P., 2015. RBFOX and PTBP1 proteins regulate the alternative splicing of micro-exons in human brain transcripts. Genome Res. 25, 1-13.

Lin, D. , Boyle, M.P. , Dollar, P. , Lee, H. , Lein, E.S. , Perona, P. , Anderson, D.J. , 2011. Functional identification of an aggression locus in the mouse hypothalamus. Nature 470, 221-226.

Luque, M.J. , Martin-Lopez, M. , Navarro, J.F. , 2009. Effects of LY379268, a selective agonist of mGLu2/3 receptors, on isolation-induced aggression in male mice. Open Pharmacol. J. 3, 1720 .

Martin, C.L. , Duvall, J.A. , Ilkin, Y. , Simon, J.S. , Arreaza, M.G. , Wilkes, K. , Alvarez-Retuerto, A. , Whichello, A. , Powell, C.M. , Rao, K. , Cook, E. , Geschwind, D.H. , 2007. Cytogenetic and molecular characterization of A2BP1/FOX1 as a candidate gene for autism. Am. J. Med. Genet. Part B Neuropsychiatr. Genet. 144, 869-876 .

Martín-García, E. , Fernández-Castillo, N. , Burokas, A. , Gutiérrez-Cuesta, J. , Sánchez-Mora, C. , Casas, M. , Ribasés, M. , Cormand, B. , Maldonado, R. , 2015. Frustrated expected reward induces differential transcriptional changes in the mouse brain. Addict. Biol. 20, 22-27 .

Melhem, N. , Middleton, F. , McFadden, K. , Klei, L. , Faraone, S.V. , Vinogradov, S. , Tiobech, J. , Yano, V. , Kuartei, S. , Roeder, K. , Byerley, W. , Devlin, B. , Myles-Worsley, M. , 2011. Copy number variants for schizophrenia and related psychotic disorders in Oceanic Palau: risk and transmission in extended pedigrees. Biol. Psychiatry 70, 1115-1121 . 
Merjonen, P. , Keltikangas-Järvinen, L. , Jokela, M. , Seppälä, I. , Lyytikäinen, L.-P. , PulkkiRåback, L. , Kivimäki, M. , Elovainio, M. , Kettunen, J. , Ripatti, S. , Kähönen, M. , Viikari, J. , Palotie, A. , Peltonen, L. , Raitakari, O.T. , Lehtimäki, T. , 2011. Hostility in adolescents and adults: a genome-wide association study of the Young Finns. Transl. Psychiatry 1, e11 .

Meyer-Lindenberg, A. , Buckholtz, J.W. , Kolachana, B., R. , Hariri, A. , Pezawas, L. , Blasi, G. , Wabnitz, A. , Honea, R. , Verchinski, B. , Callicott, J.H. , Egan, M. , Mattay, V. , Weinberger, D.R. , 2006. Neural mechanisms of genetic risk for impulsivity and violence in humans. Proc. Natl. Acad. Sci. USA 103, 6269-6274 .

Mick, E. , McGough, J. , Deutsch, C.K. , Frazier, J.A. , Kennedy, D. , Goldberg, R.J. , 2014. Genome-wide association study of proneness to anger. PLoS One 9, e87257 .

Noor, A. , Lionel, A.C. , Cohen-Woods, S. , Moghimi, N. , Rucker, J. , Fennell, A. , Thiruvahindrapuram, B. , Kaufman, L. , Degagne, B. , Wei, J. , Parikh, S.V. , Muglia, P. , Forte, J. , Scherer, S.W. , Kennedy, J.L. , Xu, W. , Mcguffin, P. , Farmer, A. , Strauss, J. , Vincent, J.B. , 2014. Copy number variant study of bipolar disorder in Canadian and UK populations implicates synaptic genes. Am. J. Med. Genet. Part B Neuropsychiatr. Genet. 165, 303-313 .

Pappa, I. , St Pourcain, B. , Benke, K. , Cavadino, A. , Hakulinen, C. , Nivard, M.G. , Nolte, I.M. , Tiesler, C.M.T. , Bakermans-Kranenburg, M.J. , Davies, G.E. , Evans, D.M. , Geoffroy, M.C. , Grallert, H. , Groen-Blokhuis, M.M. , Hudziak, J.J. , Kemp, J.P. , Keltikangas-Järvinen, L. , McMahon, G. , Mileva-Seitz, V.R. , Motazedi, E. , Power, C. , Raitakari, O.T. , Ring, S.M. , Rivadeneira, F. , Rodriguez, A., Scheet, P.A. , Seppälä, I. , Snieder, H. , Standl, M. , Thiering, E. , Timpson, N.J. , Veenstra, R. , Velders, F.P. , Whitehouse, A.J.O. , Smith, G.D. , Heinrich, J. , Hypponen, E. , Lehtimäki, T. , Middeldorp, C.M. , Oldehinkel, A.J. , Pennell, C.E. , Boomsma, D.I. , Tiemeier, H. , 2016. A genome-wide approach to children's aggressive behavior: the EAGLE consortium. Am. J. Med. Genet. Part B Neuropsychiatr. Genet. 171, 562-572 .

Passamonti, L. , Fera, F. , Magariello, A. , Cerasa, A. , Gioia, M.C. , Muglia, M. , Nicoletti, G. , Gallo, O. , Provinciali, L. , Quattrone, A. , 2006. Monoamine oxidase-a genetic variations influence brain activity associated with inhibitory control: new insight into the neural correlates of impulsivity. Biol. Psychiatry 59, 334-340 .

Potegal, M. , 2012. Temporal and frontal lobe initiation and regulation of the top-down escalation of anger and aggression. Behav. Brain Res. 231, 386-395 .

Raine, A. , Ishikawa, S.S. , Arce, E. , Lencz, T. , Knuth, K.H. , Bihrle, S. , LaCasse, L. , Colletti, P. , 2004. Hippocampal structural asymmetry in unsuccessful psychopaths. Biol. Psychiatry 55, 185-191 .

Rajman, M. , Metge, F. , Fiore, R. , Khudayberdiev, S. , Aksoy-Aksel, A. , Bicker, S. , Reschke, C.R. , Raoof, R. , Brennan, G.P., Delanty, N. , Farrell, M.A. , brien, O. , Bauer, D.F. , Norwood, S. , Veno, B. , Krüger, M.T. , Braun, M. , Kjems, T. , Rosenow, J. , Henshall, F. , Dieterich, D.C. , Schratt, G, C. , 2017. A microRNA-129-5p/Rbfox crosstalk coordinates homeostatic downscaling of excitatory synapses. EMBO J. Print . 
Sebat, J. , Lakshmi, B. , Malhotra, D. , Troge, J. , Lesemartin, C. , Walsh, T. , Yamrom, B. , Yoon, S. , Krasnitz, A. ,Kendall, J. , Leotta, A. , Pai, D. , Zhang, R. , Lee, Y. , Hicks, J. , Spence, S.J. , Lee, A.T. , Puura, K. , Lehtimäki, T. , Ledbetter, D. , Gregersen, P.K. , Bregman, J. , Sutcliffe, J.S., Jobanputra, V. , Chung, W. , Warburton, D. , 2007. Strong association of de novo copy number mutations with Autism. Science 316, 445-449 .

Sharpe, J.P. , Desai, S. , 2001. The revised neo personality inventory and the MMPI-2 psychopathology five in the prediction of aggression. Pers. Individ. Dif. 31, 505-518 .

Shorter, J. , Couch, C. , Huang, W. , Carbone, M.A. , Peiffer, J. , Anholt, R.R.H. , Mackay, T.F.C. , 2015. Genetic architecture of natural variation in Drosophila melanogaster aggressive behavior. Proc. Natl. Acad. Sci. 112, E3555-E3563.

Siddaway A.P., Taylor P.J., Wood A.M., 2017. Reconceptualizing anxiety as a contínuum that ranges from high calmness to high anxiety: the joint importance of reducing distress and increasing well-being. J. Pers. Soc. Psychol. Mar 2. 10.1037/pspp0000128 . [Epub ahead of print]

Siever, L.J. , 2008. Neurobiology of aggression and violence. Am. J. Psychiatry 165, 429-442 .

Sonuga-Barke, E.J.S. , Lasky-Su, J. , Neale, B.M. , Oades, R. , Chen, W. , Franke, B. , Buitelaar, J. , Banaschewski, T. , Ebstein, R. , Gill, M. , Anney, R. , Miranda, A. , Mulas, F. , Roeyers, H. , Rothenberger, A. , Sergeant, J. , Steinhausen, H.C. , Thompson, M. , Asherson, P. , Faraone, S.V. , 2008. Does parental expressed emotion moderate genetic effects in ADHD? An exploration using a genome wide association scan. Am. J. Med. Genet. Part B Neuropsychiatr. Genet. 147, 13591368 .

Soyka, M. , 2011. Neurobiology of aggression and violence in schizophrenia. Schizophr. Bull. 37, 913-920 .

Spielberger, C.D. , 1983. Manual for the State-Trait Anxiety Inventory (STAI). Consulting Psychologists Press, Palo Alto . Sterzer, P. , Stadler, C. , Krebs, A. , Kleinschmidt, A. , Poustka, F. , 2005. Abnormal neural responses to emotional visual stimuli in adolescents with conduct disorder. Biol. Psychiatry 57, 7-15 .

Takahashi, A. , Lee, R.X. , Iwasato, T. , Itohara, S. , Arima, H. , Bettler, B. , Miczek, K.A. , Koide, T. , 2015. Glutamate input in the dorsal raphe nucleus as a determinant of escalated aggression in male mice. J. Neurosci. 35, 6452-6463 .

Tremblay, P.F. , Ewart, L.A. , 2005. The Buss and Perry Aggression Questionnaire and its relations to values, the Big Five, provoking hypothetical situations, alcohol consumption patterns, and alcohol expectancies. Pers. Individ. Dif. 38, 337-346 .

Underwood, J.G. , Boutz, P.L. , Dougherty, J.D. , Stoilov, P. , Black, D.L. , 2005. Homologues of the Caenorhabditis elegans Fox-1 protein are neuronal splicing regulators in mammals. Mol. Cell. Biol. 25, 10005-10016 . 
Vaht, M. , Kiive, E. , Veidebaum, T. , Harro, J. , 2016. A functional vesicular monoamine transporter 1 (VMAT1) gene variant is associated with affect and the prevalence of anxiety, affective, and alcohol use disorders in a longitudinal population-representative birth cohort study. Int. J. Neuropsychopharmacol. 19, 1-9 .

van Dongen, J. , Nivard, M.G. , Baselmans, B.M.L. , Zilhão, N.R. , Ligthart, L. , Heijmans, B.T. , Bartels, M. , Boomsma, D.I. , 2015. Epigenome-wide association study of aggressive behavior. Twin Res. Hum. Genet. 18, 686-698 .

Van Praag, H.M. , 1998. Anxiety and increased aggression as pacemakers of depression. Acta Psychiatr. Scand. 98, 81-88.

Vekovischeva, O.Y. , Aitta-Aho, T. , Echenko, O. , Kankaanpää, A. , Seppälä, T. , Honkanen, A. , Sprengel, R. , Korpi, E.R. , 2004. Reduced aggression in AMPA-type glutamate receptor GluRA subunit-deficient mice. Genes Brain Behav. 3, 253-265 .

Veroude, K. , Zhang-James, Y. , Fernàndez-Castillo, N. , Bakker, M.J. , Cormand, B. , Faraone, S.V. , 2016. Genetics of aggressive behavior: an overview. Am. J. Med. Genet. Part B Neuropsychiatr. Genet 171, 3-43 .

Voineagu, I. , Wang, X. , Johnston, P. , Lowe, J.K. , Tian, Y. , Horvath, S. , Mill, J. , Cantor, R.M. , Blencowe, B.J. , Geschwind, D.H. , 2011. Transcriptomic analysis of autistic brain reveals convergent molecular pathology. Nature 474, 380-384 .

Volavka, J. , 2013. Violence in schizophrenia and bipolar disorder. Psychiatr. Danub. 25, 24-33 .

Vounou, M. , Janousova, E. , Wolz, R. , Stein, J.L. , Thompson, P.M. , Rueckert, D. , Montana, G., 2012. Sparse reduced-rank regression detects genetic associations with voxel-wise longitudinal phenotypes in Alzheimer's disease. Neuroimage 60, 700-716 .

Wang, K.S. , Liu, X.F. , Aragam, N. , 2010. A genome-wide meta-analysis identifies novel loci associated with schizophrenia and bipolar disorder. Schizophr. Res. 124, 192-199 .

Wen, M. , Yan, Y. , Yan, N. , Chen, X.S. , Liu, S.Y., Feng, Z.H. , 2015. Upregulation of RBFOX1 in the malformed cortex of patients with intractable epilepsy and in cultured rat neurons. Int. J. Mol. Med. 35, 597-606 .

Xu, B. , Roos, J.L. , Levy, S. , van Rensburg, E.J., Gogos, J.A. , Karayiorgou, M. , 2008. Strong association of de novo copy number mutations with sporadic schizophrenia. Nat. Genet. 40, 880885 .

Zapata, I. , Serpell, J.A. , Alvarez, C.E. , 2016. Genetic mapping of canine fear and aggression. BMC Genom. 17, 572 . 
Zhao, Q.-F. , Tan, L., Wang, H.-F. , Jiang, T. , Tan, M.-S. , Tan, L., Xu, W. , Li, J.-Q. , Wang, J. , Lai, T.-J. , Yu, J.-T. , 2016. The prevalence of neuropsychiatric symptoms in Alzheimer's disease: systematic review and meta-analysis. J. Affect. Disord. 190, 264-271 .

Zhao, W.-W. , 2013. Intragenic deletion of RBFOX1 associated with neurodevelopmental/neuropsychiatric disorders and possibly other clinical presentations. Mol. Cytogenet. 6, 26 .

Zhong, X. , Drgonova, J. , Li, C.Y. , Uhl, G.R. , 2015. Human cell adhesion molecules: annotated functional subtypes and overrepresentation of addiction-associated genes. Ann. NY Acad. Sci. 1349, 83-95 . 